\title{
A Review on $\mathrm{TiO}_{2}$ Nanotube Film Photocatalysts Prepared by Liquid-Phase Deposition
}

\author{
Jinshu Wang, Qian Cai, Hongyi Li, Yuntao Cui, and Hong Wang \\ School of Materials Science and Engineering, Beijing University of Technology, Beijing 100124, China \\ Correspondence should be addressed to Jinshu Wang, wangjinshu2002@hotmail.com
}

Received 15 September 2011; Revised 18 November 2011; Accepted 18 November 2011

Academic Editor: Jiaguo Yu

Copyright () 2012 Jinshu Wang et al. This is an open access article distributed under the Creative Commons Attribution License, which permits unrestricted use, distribution, and reproduction in any medium, provided the original work is properly cited.

$\mathrm{TiO}_{2}$ nanotube film is a promising photocatalyst associated with its unique physical and chemical properties such as optic, electronic, high specific surface area. Liquid-phase decomposition provides a feasible way for the preparation of functional thin film. This paper reviews and analyzes the formation mechanism of $\mathrm{TiO}_{2}$ nanotube film by liquid phase deposition. The effect of preparation parameters, such as the kinds of electrolyte solution for the preparation of anodic alumina template, volume fraction of $\mathrm{Al}_{2} \mathrm{O}_{3}$ on the template, the concentration of the deposition solution, and heat treatment, on the formation of $\mathrm{TiO}_{2}$ nanotube film has been analyzed. The effects of doping of metallic and nonmetallic elements on the photocatalytic activity of $\mathrm{TiO}_{2}$ nanotube have been discussed.

\section{Introduction}

Nowadays, humans are more and more concerned about environmental issues. Large amounts of organic pollutants are being released into the ecosystem over the past few decades and they cause a serious threat to the environment [1]. Researchers all over the world have been working on various approaches to address the issue. In the past decades, the traditional physical techniques, such as adsorption, biological treatment, coagulation, ultrafiltration, and ion exchange on synthetic resins, have been adopted for the removal of organic pollutants from wastewaters [2]. However, these methods might cause secondary pollution, and degradation of organic pollutants is usually incomplete and selective.

Since the discovery of photocatalytic splitting of water on $\mathrm{TiO}_{2}$ electrodes by Fujishima and Honda in 1972 [3], heterogeneous photocatalysis has attracted much attention as a new purification technique for air and water [4-6]. Titania nanostructures have been widely investigated for applications in optical devices [7], gas sensors [8], and dyesensitized solar cells [9]. Titania semiconductor photocatalysts have demonstrated advantages such as transparency [10], wide bandgap [11], biological and chemical inertness $[12,13]$, strong oxidizing capability, and nontoxicity [14]. So titania exhibits good performance on the degradation of organic pollutants under ultraviolet radiation. Many other photocatalysts such as $\mathrm{CdS}, \mathrm{WO}_{3}$, and $\mathrm{SrTiO}_{3}$ also exhibit a certain photocatalytic activity [15-17].

Crystalline titania has many morphologies such as nanofibers, nanoparticles, nanorods, nanospheres, nanotubes, and nanowires [18-20]. Titania nanotubes are highly efficient in photocatalysis since titania nanotubes have a relatively higher interfacial charge transfer rate and surface area compared with the spherical $\mathrm{TiO}_{2}$ particles [21]. Many approaches have been developed for the preparation of $\mathrm{TiO}_{2}$ nanotubes, that is, chemical vapor deposition (CVD), anodic oxidation, seeded growth, the wet chemical (hydrothermal method and the sol-gel method) [22-24], and liquid-phase deposition of templates. Among these methods, liquid-phase deposition (LPD) of template method is one of the simplest and most practical one to fabricate $\mathrm{TiO}_{2}$ nanotubes, since it has so many advantages such as low cost, mild reaction condition, simple equipment requirement and allows $\mathrm{TiO}_{2}$ films to be deposited over large areas.

\section{Liquid-Phase Deposition of Template Method: Formation of Titania Nanotubes}

A variety of oxide nanohole sheets have been prepared by a liquid-phase deposition method. The liquid-phase deposition can be applied readily to the preparation of thin films 
on various types of substrates with large surface areas and a variety of morphologies, since the LPD is performed in an aqueous solution. In the LPD process, using anodic alumina template as a scavenger and starting materials, the metal oxide films can be fabricated by only one-step reaction. The liquid-phase deposition of template method consists of two major steps: (a) preparation of anodic aluminum oxide templates; (b) liquid-phase deposition.

Anodic alumina oxide (AAO) has been used as template for the fabrication of several kinds of functional devices with nanometer dimensions due to its unique structure, such as controllable pore diameter, extremely narrow pore size distribution, and ideally cylindrical pore shape [25-30]. Since the diameter of the cylindrical pores of the templates can be varied between 10 and $200 \mathrm{~nm}$ by altering the preparation conditions, the templating method has a number of interesting and useful features for the production of microscopically tailored materials [31]. The AAO films with an ordered array of holes [32-36] can be used as templates for the preparation of nanotubes, nanowires [37-42], nanodots, and nanopillars [43-45] as well as micro-electromechanical systems (MEMSs) devices [46]. The AAO films with pore diameter ranging from 4 to $250 \mathrm{~nm}$, density as high as $10^{11}$ pores $/ \mathrm{cm}^{-1}$, and film thickness varying from 0.1 to $300 \mu \mathrm{m}$, have been realized [37, 38]. The anodic aluminum oxide template has been widely applied in the preparation of various nanomaterials. Highly ordered polycrystalline Si nanowire arrays were synthesized with porous anodic aluminum oxide templates by chemical vapor deposition [47].

We made the highlighted changes according to the list to references. Please check.

Yamanaka et al. have prepared titania nanotubes successfully with anodic aluminum oxide (AAO) templates as precursor by liquid-phase deposition method [48] and the morphology of the AAO templates and titania nanotubes formed is shown in Figure 1. The AAO templates have many pores and their mean sizes are approximately $200 \mathrm{~nm}$ (Figure 1(a)), and titania nanotubes formed keep the morphology of AAO with nearly the same size (Figure 1(b)). The titania nanotubes array which consist of many grains with approximately $20 \mathrm{~nm}$ in diameter have the thickness as high as about $50 \mu \mathrm{m}$, as shown in Figures 1(c) and 1(d). In the past, AAO templates had to be stripped from the aluminum substrates and removed the barrier layers. However, the AAO templates made in this way are brittle, so it is limited to fabricate large area nanotube array. Jiang et al. prepared titania nanotubes in a large scale by LPD method using AAO templates without stripping from the Al substrates [49], which provided a simple and feasible way for the preparation of the $\mathrm{TiO}_{2}$ films in a large scale.

\section{Liquid-Phase Deposition of Template Method: Formation Mechanism of Titania Nanotubes}

3.1. Formation Mechanism of AAO Template. The titania nanotubes are synthesized in situ on the anodic aluminum oxide templates. So the morphology of the titania nanotubes is correlated with the morphology of AAO templates. There are two types of aluminum oxide films prepared by anodizing the aluminum: barrier type and porous type [50]. The barrier-type AAO template is formed by anodizing $\mathrm{Al}$ foil in the electrolyte solution such as citric acid, boric acid, and glycolic acid in which $\mathrm{Al}$ has very low solubility. However, the porous-type AAO template can be formed by anodizing in the electrolyte solution such as sulfuric acid, oxalic acid, and phosphoric acid in which $\mathrm{Al}$ has better solubility. Taking oxalic acid as an example, the reaction equations can be written as below [51].

Cathode Reaction:

$$
\begin{gathered}
2 \mathrm{H}^{+}+2 e \longrightarrow \mathrm{H}_{2} \uparrow \\
\mathrm{C}_{2} \mathrm{O}_{4}{ }^{2-}+6 \mathrm{H}^{+}+4 \mathrm{e} \longrightarrow \mathrm{CH}_{2} \mathrm{OH} \cdot \mathrm{COOH}+\mathrm{H}_{2} \mathrm{O}
\end{gathered}
$$

Anode Reaction:

$$
\begin{gathered}
6 \mathrm{OH}^{-}-6 \mathrm{e} \longrightarrow 3 \mathrm{H}_{2} \mathrm{O}+3[\mathrm{O}] \\
2 \mathrm{Al}+3[\mathrm{O}] \longrightarrow \mathrm{Al}_{2} \mathrm{O}_{3} \\
\mathrm{Al}-3 \mathrm{e} \longrightarrow \mathrm{Al}^{3+} \\
\mathrm{H}_{2} \mathrm{C}_{2} \mathrm{O}_{4}-2 \mathrm{e} \longrightarrow 2 \mathrm{H}^{+}+2 \mathrm{CO}_{2}
\end{gathered}
$$

At the beginning of the anodizing process, the amorphous oxide is formed. Oxide is dissolved with the electric field enhancement, leading to the formation of porous oxide.

3.2. Formation Mechanism of Titania Nanotubes. Imai et al. first reported that crystalline titania films could be deposited from aqueous solutions of $\mathrm{TiF}_{4}$ at $\mathrm{PH} 1-3$ and the hydrolysis of $\mathrm{TiF}_{4}$ in solution occurred in a stepwise manner to produce titania [31]:

$$
\mathrm{TiF}_{4} \longrightarrow \mathrm{Ti}(\mathrm{OH})_{4-x} \mathrm{~F}_{x} \longrightarrow \mathrm{TiO}_{2}
$$

Titania forms on the inner walls of the nanochannels of the alumina template through heterogeneous nucleation and then grows into nanotubes which keep the porous morphology of alumina.

Using anodic alumina films as the templates, the following chemical reactions might take place:

$$
\begin{gathered}
{\left[\mathrm{TiF}_{6}\right]^{2-}+(n+2) \mathrm{H}_{2} \mathrm{O} \Longleftrightarrow \mathrm{TiO}_{2} \cdot n \mathrm{H}_{2} \mathrm{O}+4 \mathrm{H}^{+}+6 \mathrm{~F}^{-}} \\
\mathrm{Al}_{2} \mathrm{O}_{3}+12 \mathrm{H}^{+}+12 \mathrm{~F}^{-} \Longleftrightarrow 2 \mathrm{H}_{3} \mathrm{AlF}_{6}+3 \mathrm{H}_{2} \mathrm{O}
\end{gathered}
$$

Therefore, $\mathrm{TiO}_{2}$ can be formed by the hydrous reaction of $\mathrm{TiF}_{6}{ }^{2-}$ accompanied by an $\mathrm{F}^{-}$consuming reaction, where $\mathrm{Al}_{2} \mathrm{O}_{3}$ is taken as scavenger for $\mathrm{F}^{-}$. The equilibrium reaction (8) is shifted to the right side by the reaction of $\mathrm{Al}_{2} \mathrm{O}_{3}$, $\mathrm{H}^{+}$and $\mathrm{F}^{-}$, since $\mathrm{Al}_{2} \mathrm{O}_{3}$ reacts readily with $\mathrm{F}^{-}$ions to give the more stable $\mathrm{AlF}_{6}{ }^{3-}$. The product $\mathrm{TiO}_{2} \cdot n \mathrm{H}_{2} \mathrm{O}$ deposits in situ on anodic alumina template. We present an illustration for the formation of titanium hydrous oxide nanotubes array films [52], as shown in Figure 2. When the AAO templates are immersed into $\left(\mathrm{NH}_{4}\right)_{2} \mathrm{TiF}_{6}$ solution, 


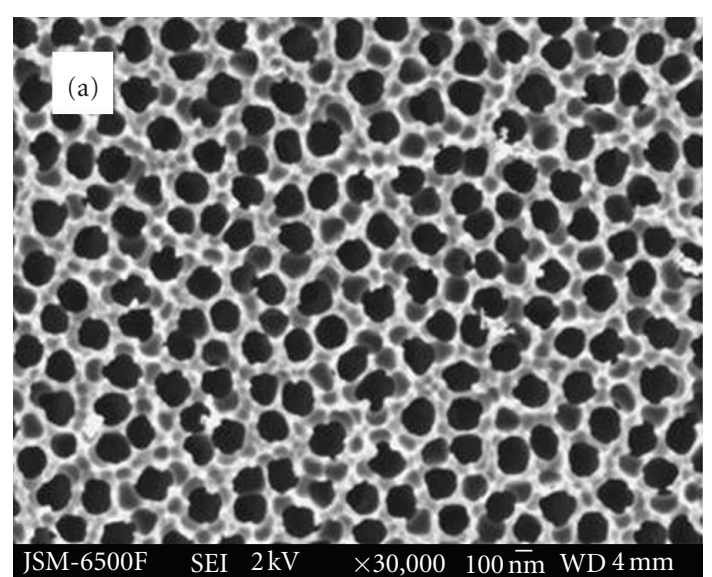

(a)

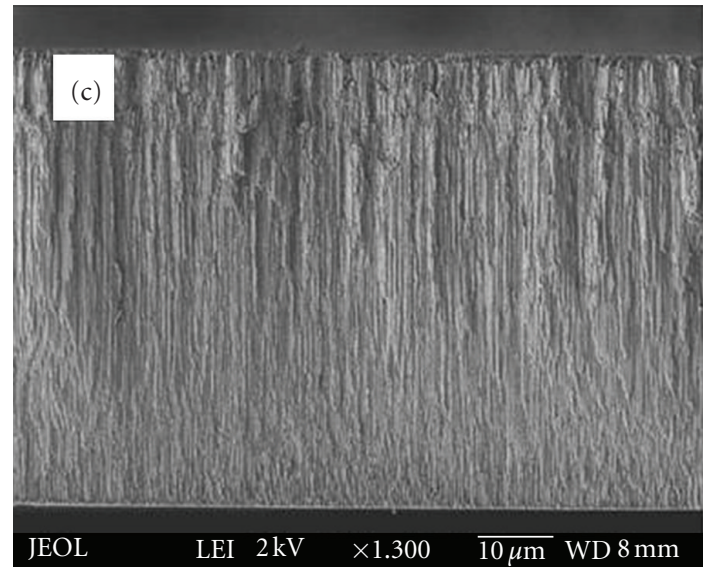

(c)

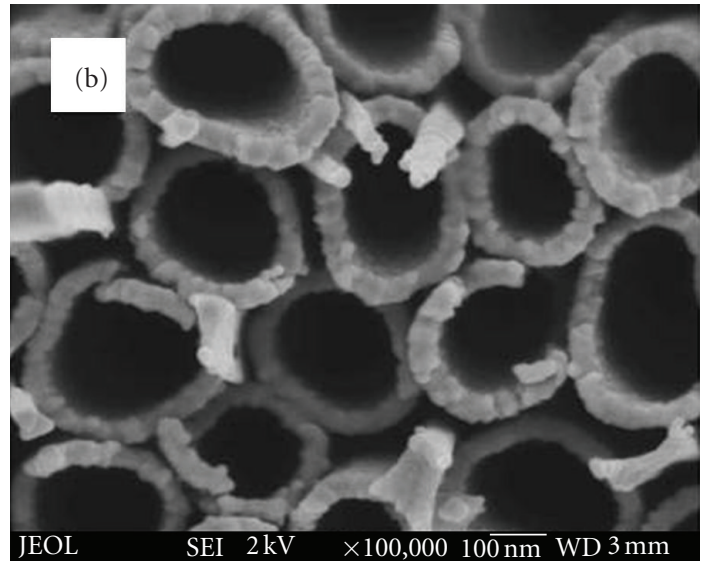

(b)

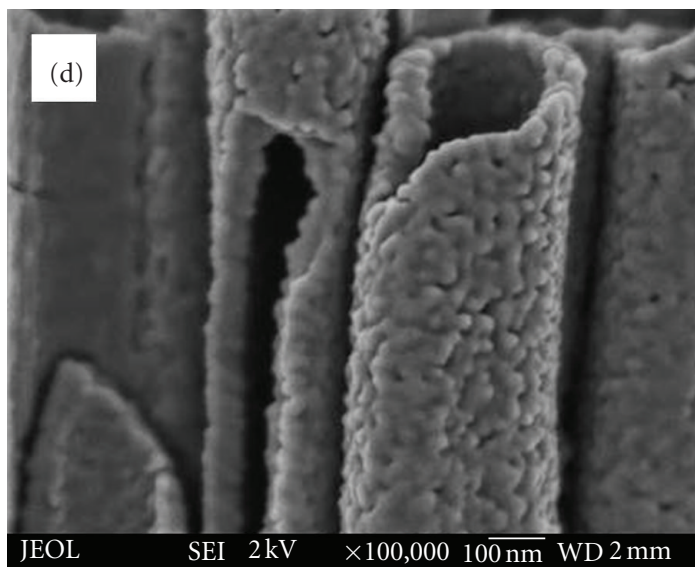

(d)

FIGURE 1: FE-SEM photographs of the titania nanohole arrays: (a) surface morphology of anodic alumina as starting material, (b) surface morphology of titania nanohole array, (c) cross-section of titania nanohole array, and (d) cross-section detailing (c) [48].

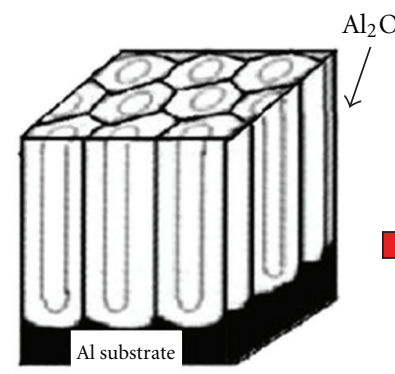

(a)

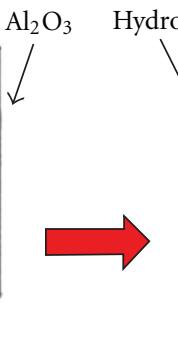

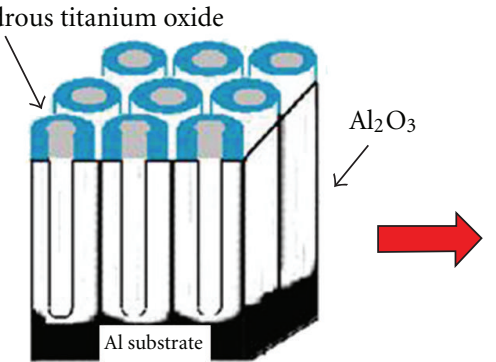

(b)

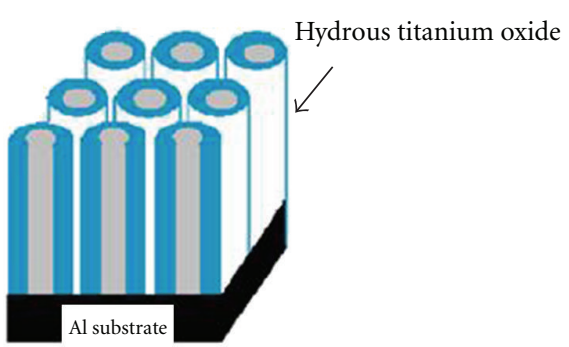

(c)

FIgURE 2: Schematic diagram of the formation of the titania nanohole array: (a) before deposition, (b) during deposition, and (c) after deposition [52].

the hydrolysis of reaction of $\left[\mathrm{TiF}_{6}\right]^{2-}$ takes place at the surface. Hydrous titanium oxide deposits in situ on the AAO templates, accompanied with the consumption of AAO templates, as shown in Figure 2(b). Hydrous titanium oxide is formed from the surface to the inner part of AAO template with the prolonging of the reaction time (Figure 2(c)). After calcinations, $\mathrm{TiO}_{2}$ nanotubes can be formed.
Kanawori et al. described the formation mechanism by the addition of boric acid [43] which is used as scavenger for $\mathrm{F}^{-}$ion. The reactions are shown below.

$$
\begin{gathered}
{\left[\mathrm{TiF}_{6}\right]^{2-}+n \mathrm{H}_{2} \mathrm{O} \Longleftrightarrow\left[\mathrm{Ti}_{6-n}(\mathrm{OH})_{n}\right]^{2-}+n \mathrm{HF}} \\
\mathrm{BO}_{3}{ }^{3-}+4 \mathrm{~F}^{-}+6 \mathrm{~h}^{+} \Longleftrightarrow \mathrm{BF}^{-}+3 \mathrm{H}_{2} \mathrm{O}
\end{gathered}
$$


Boric acid promotes reaction (10) to the right side by consuming $\mathrm{F}^{-}$, leading to the formation of hydrous titanium oxide.

\section{Factors Influencing the Formation and Photocatalytic Activity of Titania Nanotube Film}

There are several factors which affect the formation of titania nanotubes: (a) the electrolyte solution used to prepare AAO templates (such as phosphoric acid, oxalic acid, and sulfuric acid), (b) oxidation temperature, (c) anodizing voltage, (d) oxidation time, (e) the concentration of the deposition solution, (f) deposition temperature, (g) deposition time, and $(\mathrm{h})$ the temperature of heat treatment. These factors can be summarized as (1) the preparation parameters of AAO template, (2) liquid-phase deposition parameters, (3) Heat treatment. The characteristics and morphology of titania nanotubes such as specific surface area, film thickness, crystal structure and others are dependent on the selected abovementioned conditions.

4.1. Effect of Preparation Parameters of AAO Template on the Morphology of $\mathrm{TiO}_{2}$ Nanoarrays. The AAO templates are prepared with a modified two-step anodization process. The pore size, pore density, and the thickness of the AAO template are approximately proportional to the anodization voltage, but the quality of the ordering in the AAO structure also highly depends on the first anodization time [34]. Zhang et al. anodized aluminum in a $0.3 \mathrm{M}$ oxalic acid solution with outer voltage of $40 \mathrm{~V}$ at $0^{\circ} \mathrm{C}$ for different time. After removing the preliminary oxidization layer, the second anodization was carried out at $0^{\circ} \mathrm{C}$ for about $1 \mathrm{~h}$ under the same conditions as the first anodization step. Afterward, the AAO template was immersed into a $5 \mathrm{wt} \%$ phosphoric acid solution to widen the nanochannels. The outer diameter of the AAO pore is $180 \mathrm{~nm}$, and the wall thickness of the AAO pore is $55 \mathrm{~nm}$ [53]. Jiang et al. used 10\% phosphoric acid instead of oxalic acid to oxidize aluminum with outer voltage of $120 \mathrm{~V}$ at room temperature for $1 \mathrm{~h}$. Then the aluminum was immersed in the $1.8 \% \mathrm{H}_{2} \mathrm{CrO}_{4}: 6 \% \mathrm{H}_{3} \mathrm{PO}_{4}=$ $1: 1$ (volume ratio) mixed solution to remove preliminary oxidization layer. The second anodization step was the same as the first anodization step but for $4 \mathrm{~h}$ [49]. After widening the nanochannels, the AAO templates were obtained with larger aperture than the AAO templates made in oxalic acid. We also find in our work that the anodic alumina templates prepared in oxalic acid have relatively small pore diameter, as shown in Figure 3(a). The mean outside diameter and inside diameter of that prepared in oxalic acid are about $100 \mathrm{~nm}$ and $25 \mathrm{~nm}$, respectively. On the other hand, the templates prepared in phosphoric acid have large pore diameter, as shown in Figure 3(b), that is, the mean outside diameter of the tubule and inside diameter are about $250 \mathrm{~nm}$ and $150 \mathrm{~nm}$, respectively. The pores in all the templates are uniform and arranged regularly. The pore size formed in the membrane is related to the anodizing voltage applied in the electrolyte. It is reported that the maximum anodizing voltage applied in the electrolyte is in the order phosphoric acid > oxalic acid. The anodizing process will be blocked when a voltage higher than $V_{\max }$ is employed. To obtain the template with large pores, high anodizing voltage should be applied in the electrolyte; therefore, anodic alumina template prepared with phosphoric acid has the larger pore size.

We have studied the relationship between volume fraction of $\mathrm{Al}_{2} \mathrm{O}_{3}$ in the template and the morphology of $\mathrm{TiO}_{2}$ nanoarray [54]. When the volume fraction of $\mathrm{Al}_{2} \mathrm{O}_{3}$ in the template is more than 0.71 , such as the template prepared in oxalic acid, the ordered aligned titania nanorods can be obtained (Figure 3(c)) whereas the ordered aligned titania nanotubes can be synthesized when the volume fraction of $\mathrm{Al}_{2} \mathrm{O}_{3}$ in the template (e.g., the template prepared in phosphoric acid) is less than 0.71, as shown in Figure 3(d). Therefore, the morphology of $\mathrm{TiO}_{2}$ nanoarray depends on the volume fraction of $\mathrm{Al}_{2} \mathrm{O}_{3}$ in the template which can be controlled by the preparation parameters of AAO templates.

4.2. Effect of Concentration of the Deposition Solution. The concentration of the deposition solution should be controlled in an appropriate value. In our study, it is found that $0.1 \mathrm{~mol} / \mathrm{L}\left(\mathrm{NH}_{4}\right)_{2} \mathrm{TiF}_{6}$ is suitable for the deposition, and the morphology of $\mathrm{TiO}_{2}$ nanotube is shown in Figure 4(b). If the concentration of the deposition solution is too low, only a small number of $\mathrm{TiO}_{2}$ nanotubes can be produced with a large amount of alumina remained, as shown in Figure 4(a). If the concentration of the deposition solution is too high, the reaction is so severe that parts of $\mathrm{TiO}_{2}$ nanotubes will be destroyed (Figure 4(c)).

4.3. Effect of Heat Treatment. $\mathrm{TiO}_{2}$ prepared by LPD method exhibits as amorphous phase [57]. It is well known that it shows poor photocatalytic activity since amorphous $\mathrm{TiO}_{2}$ has defects in its crystal structure. To prepare anatase $\mathrm{TiO}_{2}$ with a high surface area and good crystallization is essential to improve the photocatalytic activity. Calcination is a simple way for the crystallization of $\mathrm{TiO}_{2}$. When annealing at $400^{\circ} \mathrm{C}$ for $2 \mathrm{~h}$, the amorphous $\mathrm{TiO}_{2}$ films change to anatase phase $[52,58]$. With increasing calcination temperature, the photocatalytic activity increases due to the formation of anatase $\mathrm{TiO}_{2}$ and the improvement of crystallization [59]. With further increase in the calcination temperature from 600 to $800^{\circ} \mathrm{C}$, the photocatalytic activity rapidly decreased due to the vanishing of anatase phase, collapse of nanotube structures, and decrease of surface areas $[60] . \mathrm{TiO}_{2}$ has three types of crystal structures: anatase, rutile, and brookite. Among them, the anatase films show best photocatalytic property. It is also found that a mixed phase of anatase and rutile or brookite shows excellent photocatalytic ability [61] due to the reduction of the combination probability of the hole-electron pairs.

Recently, vapor-thermal treatment can be applied to the crystallization of $\mathrm{TiO}_{2}$. In vapor-thermal treatment, the asprepared $\mathrm{TiO}_{2}$ nanotube array film was placed on the support to avoid direct contact with the water, which was then placed into a $100-\mathrm{mL}$ stainless steel autoclave with a $100 \mathrm{~mL}$ Teflon linear. Two $\mathrm{mL}$ distilled water was added into the linear. This method is different from hydrothermal method, 


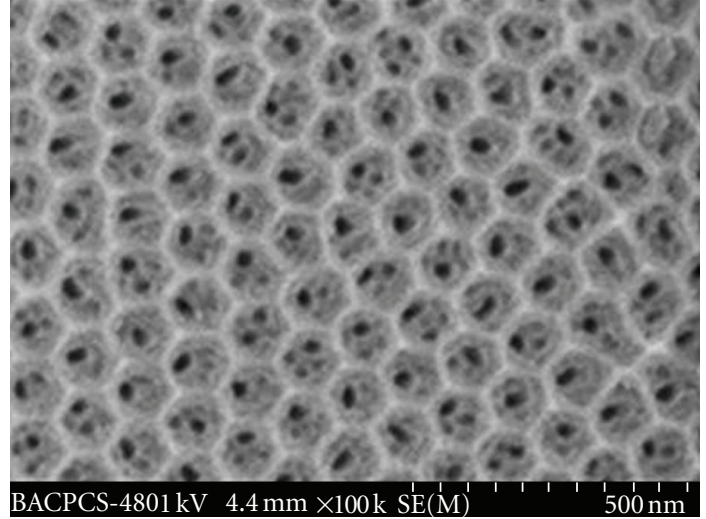

(a)

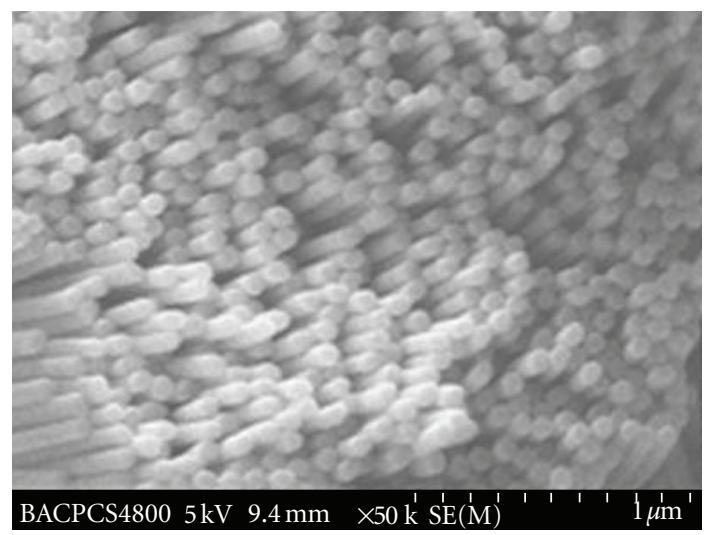

(c)

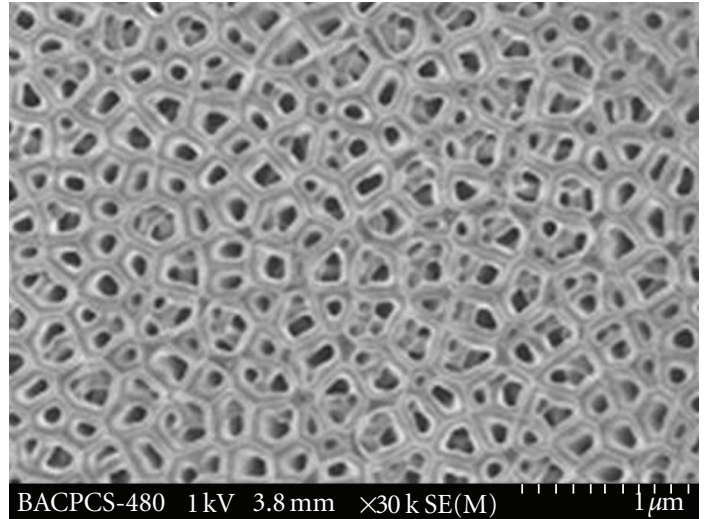

(b)

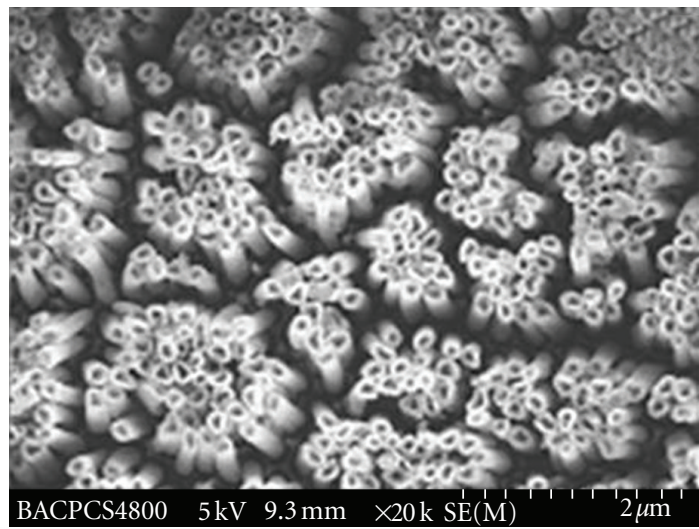

(d)

Figure 3: FE-SEM of titanium oxide nanotubes array films: (a) AAO membrane (oxalic acid), (b) AAO membrane (phosphoric acid), (c) surface morphology of titanium oxide nanotubes array films (oxalic acid), and (d) surface morphology of titanium oxide nanotubes array films (phosphoric acid) [54].

in which the $\mathrm{TiO}_{2}$ nanotube array film was put into Teflonlined autoclave, which was then filled with water up to $80 \%$ of the total volume. The vapor-thermal-treated films have better crystallization than the calcined films and remained tubular structures compared with the hydrothermal-treated samples. So the vapor-thermal treatment exhibits better photocatalytic activity than the calcined and hydrothermal treated films (Figure 5) [55].

\section{Modification of Titania Nanotube Photocatalysts}

In order to improve the photocatalytic activity, various approaches, such as nonmetal anions doping, surface improvement with noble metal, transition metal cation doping, and semiconductor composite, have been attempted to hamper the recombination of the photogenerated hole-electron pairs in the photocatalysis [62].

Nonmetal dopants, such as N, S, C, and P have been applied in the photocatalysis to broaden the utilization of solar energy in visible region [63-65]. Asahi et al. [66] found that the substitutional doping of $\mathrm{N}$ was the most effective for its contribution to the bandgap narrowing by mixing its $\mathrm{p}$ states with $\mathrm{O} 2 \mathrm{p}$ states. Although doping with $\mathrm{S}$ shows a similar band-gap narrowing, it is difficult to incorporate it into the $\mathrm{TiO}_{2}$ lattice. The states introduced by $\mathrm{C}$ and $\mathrm{P}$ are too deep in the gap to overlap sufficiently with the band states of $\mathrm{TiO}_{2}$ to transfer photoexcited carriers to reactive sites at the catalyst surface within their lifetime. However, sulfur doping has been reported to have better photoabsorption as compared to nitrogen doping [63]. Compared with the single-element doping, the codoped $\mathrm{TiO}_{2}$ can provide better photocatalytic performance. Synergistic effect of doped $S$ and $\mathrm{N}$ forms a new band above the valence band and narrows the band-gap of the photocatalyst, leading to photo-absorption and catalytic activity in the visible light region [67].

Some researchers fabricated metal-doped $\mathrm{TiO}_{2}$ films. Zhao et al. successfully prepared $\mathrm{Zn}$-doped titania nanotubes, which was about $20 \mathrm{~nm}$ red shift in the spectrum of UV-vis absorption compared with $\mathrm{TiO}_{2}$ nanotubes [68]. Fedoped titania nanotubes improve the photocatalytic ability of titania by hindering the recombination of photogenerated hole electron and a stronger absorption in the $410-650 \mathrm{~nm}$ range $[69,70]$. The photocatalytic performance of a series of $\mathrm{Pt} / \mathrm{RE} / \mathrm{TiO}_{2}$ photocatalysts has been investigated. The activities of all rare-earth-doped $\mathrm{TiO}_{2}$ samples have been 


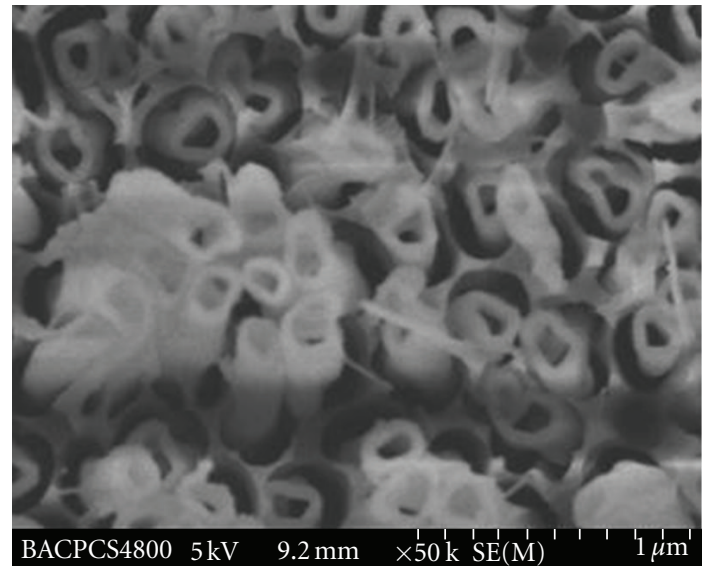

(a)

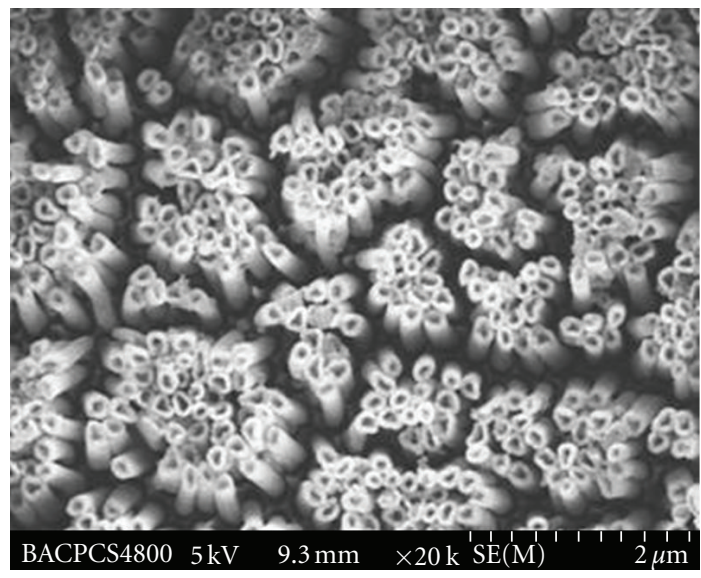

(b)

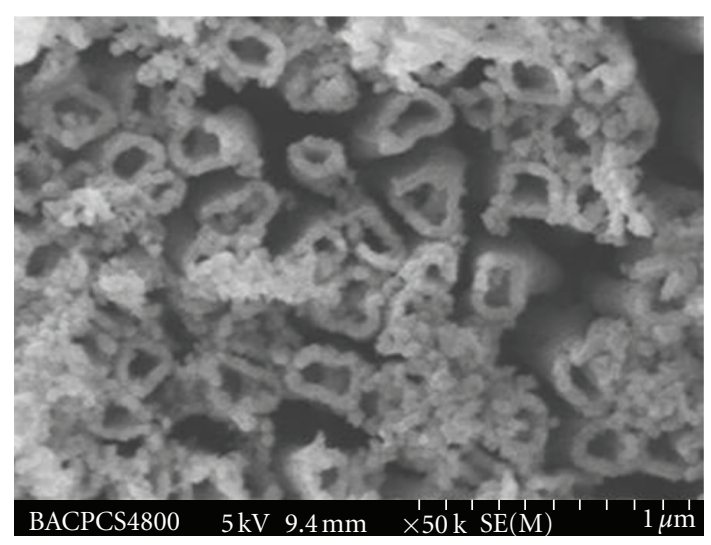

(c)

FIGURE 4: SEM micrographs of $\mathrm{TiO}_{2}$ nano tubes prepared with different concentration of deposition solution $\left(\left(\mathrm{NH}_{4}\right)_{2} \mathrm{TiF}_{6}\right):(\mathrm{a}) 0.05 \mathrm{~mol} / \mathrm{L}$, (b) $0.1 \mathrm{~mol} / \mathrm{L}$, (c) $0.3 \mathrm{~mol} / \mathrm{L}$.

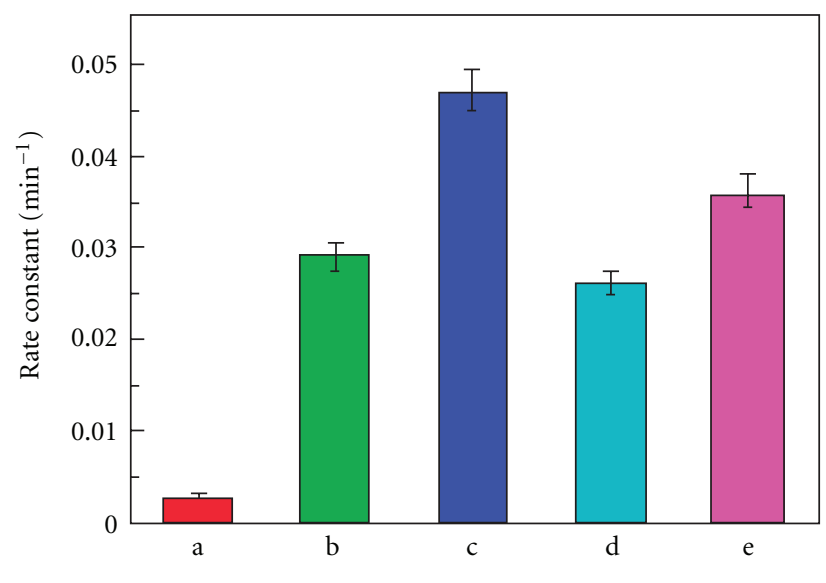

(A)

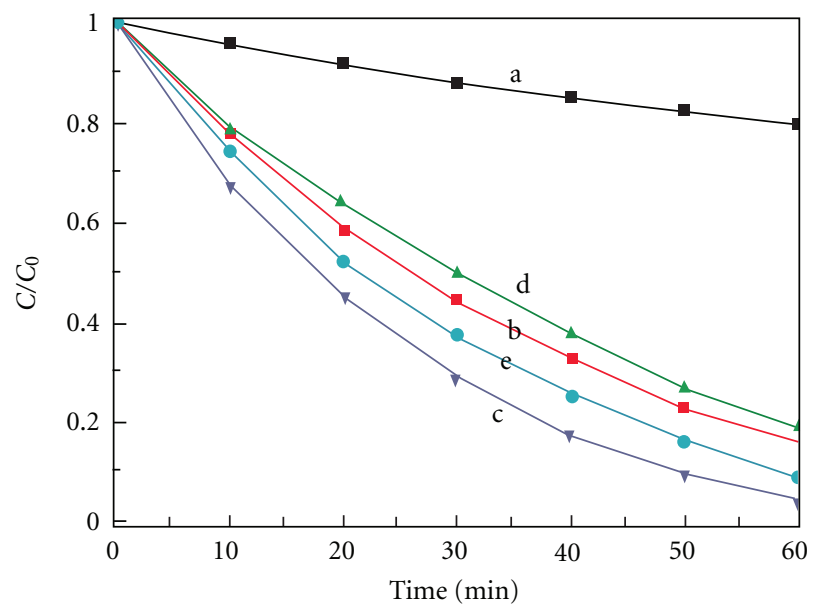

(B)

FIgURE 5: Comparison of photocatalytic activity of the TNs samples before and after treatment for the photocatalytic decomposition of MO in water: (a) untreated, (b) calcination, (c) vapor thermal, and (d) hydrothermal. (A) Apparent rate constants. (B) $C / C_{0}-t$ curve. $C$ and $C_{0}$ denote the reaction and initial concentration of MO in the system, respectively [55]. 


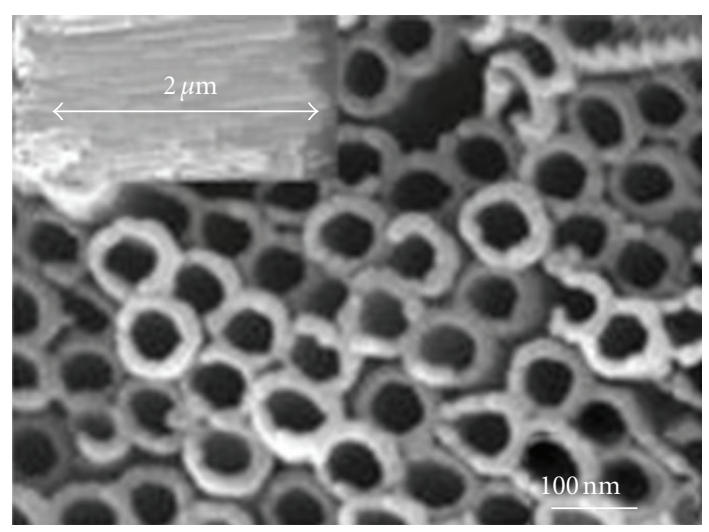

(a)

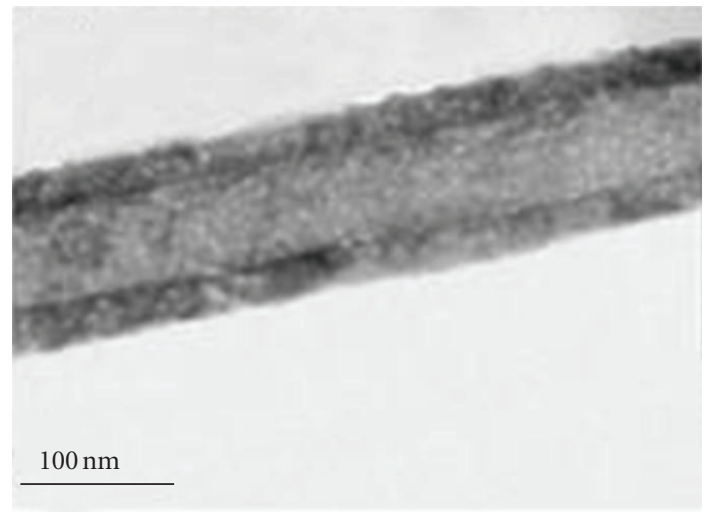

(c)

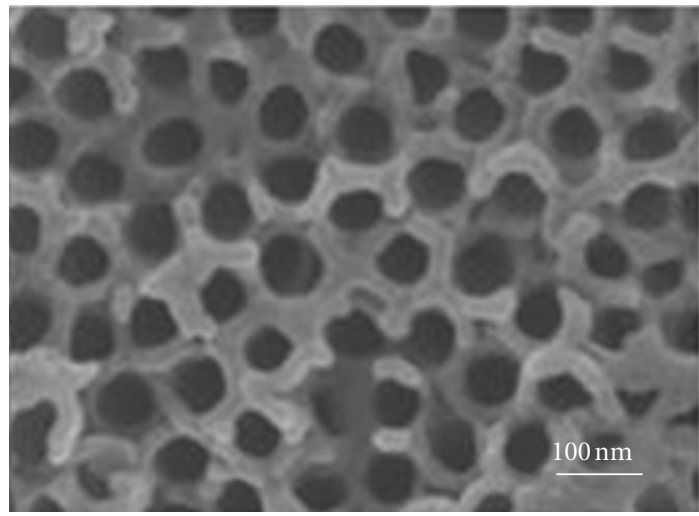

(b)

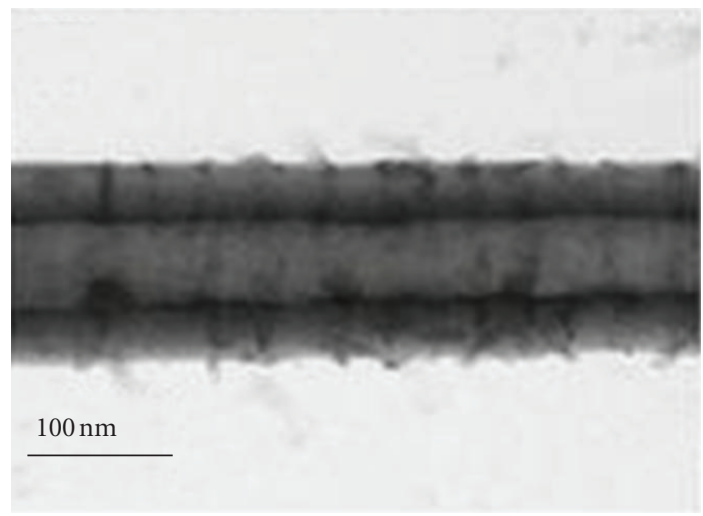

(d)

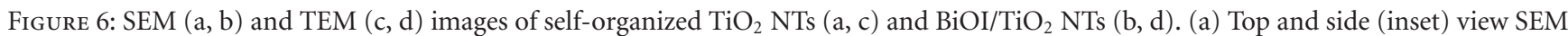
images of the unmodified $\mathrm{TiO}_{2}$ NTs. (b) Top SEM image of $\mathrm{BiOI} \mathrm{TiO}_{2}$ NTs. (c) TEM images of the unmodified TiO $\mathrm{NTs}$. (d) TEM images of $\mathrm{BiOI} / \mathrm{TiO}_{2}$ NTs [56].

increased compared to those of pure $\mathrm{TiO}_{2}$ in the order: $\mathrm{La} / \mathrm{TiO}_{2}>\mathrm{Sm} / \mathrm{TiO}_{2}>\mathrm{Eu} / \mathrm{TiO}_{2}>\mathrm{Dy} / \mathrm{TiO}_{2}>\mathrm{Er} / \mathrm{TiO}{ }_{2}$. It is shown that the transformation from anatase to rutile has been prevented, which can enhance the activities of the photocatalysts. The data of lattice distortion implies that $\mathrm{Ti}^{4+}$ can enter (antidope) into rare earth oxide that exists on the surface of titanium dioxide. The flat-band potential of conduction of $\mathrm{RE} / \mathrm{TiO}_{2}$ has been shifted negatively since the lattice distortion raises the Fermi level, which causes flat-band potential of the conduction of $\mathrm{TiO}_{2}$. As a result, the photoinduced electrons of the conduction band have stronger reduction capability and thus the photocatalytic activity is improved [71].

Chen et al. studied the doping effect of eight transition metal ion dopants on the crystal phase and the photoreactivity of $\mathrm{TiO}_{2}$ nanoparticles [72]. Among all the eight doping metal ions of $\mathrm{Zn}^{2+}, \mathrm{Fe}^{3+}, \mathrm{Cu}^{2+}, \mathrm{Co}^{2+}, \mathrm{Ni}^{2+}, \mathrm{Cr}^{3+}$, $\mathrm{V}^{5+}$, and $\mathrm{Mn}^{2+}, \mathrm{Fe}^{3+}$ and $\mathrm{Ni}^{2+}$ ions doping can improve the photocatalytic activity of $\mathrm{TiO}_{2}$ effectively. In general, red shift occurs to Ni-doped $\mathrm{TiO}_{2}$ nanoparticles. Among the ions investigated, Ni-doped $\mathrm{TiO}_{2}$ nanoparticles have shown highest photoreactivity at the concentration of 0.002 at.\%, about 1.9 times that of the pure $\mathrm{TiO}_{2}$. Ion doping is shown to reduce the diameter and influence the fraction of anatase.
Data also indicates that the combination of anatase diameter and ion radius might play an important role in the photoreactivity of $\mathrm{TiO}_{2}$ nanoparticles. Apart from the transition metal ions shown above, the noble metal nanoparticles such as silver can also improve the photocatalytic activity of $\mathrm{TiO}_{2}$ [73].

Coupling $\mathrm{TiO}_{2}$ films with other semiconductors is considered as a good way because coupling two semiconductors with different redox energy levels can increase the charge separation for their corresponding conduction and valence bands $[74,75] . \mathrm{WO}_{3}$ is an appropriate material to couple with $\mathrm{TiO}_{2}$ because $\mathrm{WO}_{3}$ has a suitable conduction band potential to allow the transfer of photogenerated electrons from $\mathrm{TiO}_{2}$ facilitating effective charge separation [76]. However, coupled $\mathrm{WO}_{3}$ did not shift the optical absorption to the visible region. The improvement of photocatalytic activity is attributed to the increased surface acidity, better separation between photoinduced carriers, and higher content of anatase [77]. BiOI is an attractive p-type semiconductor with a narrow bandgap of $1.94 \mathrm{eV}$, which is introduced to prepare p-n junction $\mathrm{BiOI} / \mathrm{TiO}_{2}$ nanotube arrays. After being coated with $\mathrm{BiOI}$, the space between individual nanotube of $\mathrm{TiO}_{2}$ has been filled and the wall thickness of $\mathrm{TiO}_{2}$ nanotubes increases by ca. $8 \mathrm{~nm}$ (Figure 6). Meanwhile, the Fermi level 


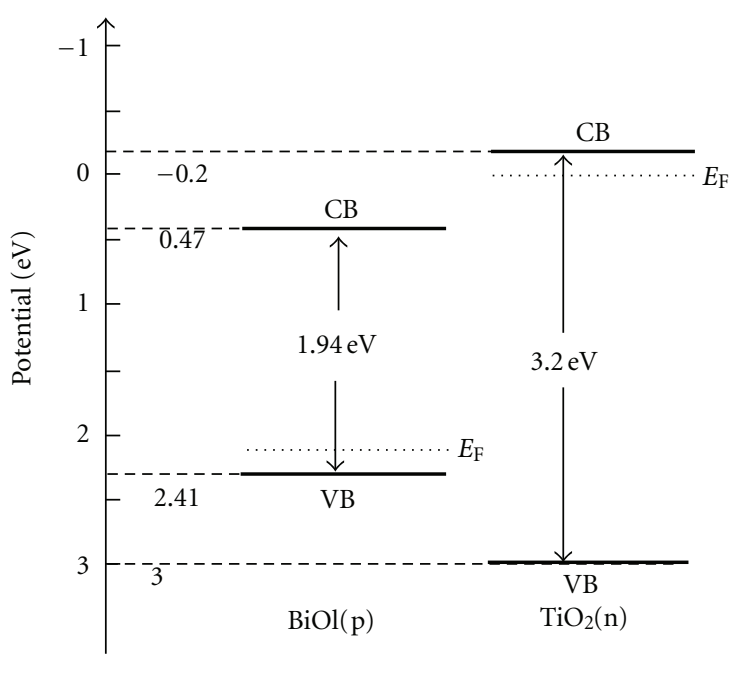

Before contact

(a)

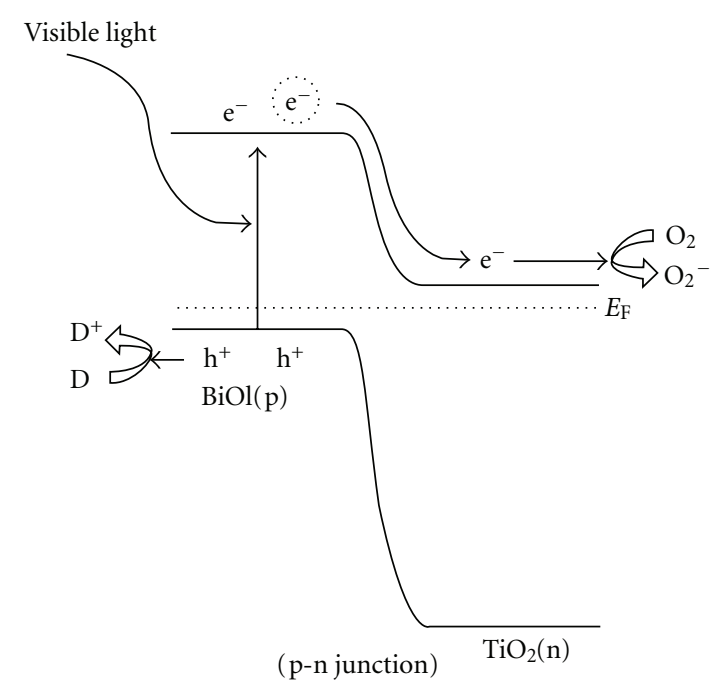

After contact

(b)

FIgURE 7: Schematic diagrams for (a) energy bands of $\mathrm{p}$ - $\mathrm{BiOI}$ and $n-\mathrm{TiO}_{2}$ before contact and (b) the formation of a p-n junction and its energy band diagram at equilibrium and transfer of photoinduced electrons from p-BiOI to $n$ - $\mathrm{TiO}_{2}$ under visible-light irradiation [56].

of $\mathrm{BiOI}$ is moved up, while the Fermi level of $\mathrm{TiO}_{2}$ is moved down until an equilibrium state is formed (Figure 7). Thus, the photogenerated electron-hole pairs will be separated effectively by the $\mathrm{p}-\mathrm{n}$ junction formed in the $\mathrm{p}-\mathrm{BiOI} / \mathrm{n}$ $\mathrm{TiO}_{2}$ interface, and the recombination of electron-hole pairs can be reduced. So the p-n junction $\mathrm{BiOI} / \mathrm{TiO}_{2}$ nanotube arrays can display much greater photoelectrocatalytic activity under visible-light irradiation [56]. We prepared $\mathrm{TiO}_{2} / \mathrm{SiO}_{2}$ composite nanotube photocatalysts by the anodic aluminum oxide (AAO) liquid-phase deposition method [78]. The Ti$\mathrm{O}-\mathrm{Si}$ bonds are formed on the surface and the surface hydroxyl concentration is increased, resulting in enhanced photocatalytic activity, being about $20 \%$ higher than pure $\mathrm{TiO}_{2}$ films. Moreover, the $\mathrm{TiO}_{2} / \mathrm{SiO}_{2}$ composite exhibits a wider conduction band which would effectively prohibit recombination of photogenerated electrons and holes.

\section{Conclusions}

This paper reviews a serial study of $\mathrm{TiO}_{2}$ nanotube films prepared by liquid-phase deposition based on the templatebased growth. The formation mechanisms of anodic alumina template and $\mathrm{TiO}_{2}$ nanotube film have been discussed. The morphology of $\mathrm{TiO}_{2}$ is affected by the morphology of anodic alumina. High anodizing voltage and phosphoric acid are favorable for the formation of large pore alumina template. The volume of alumina in the template affects the morphology of $\mathrm{TiO}_{2}$ nanoarray films. Using the template with a certain volume fraction of $\mathrm{Al}_{2} \mathrm{O}_{3}$ (less than 0.71), the ordered aligned titania nanotubes can be obtained. Proper concentration of deposition solution $(0.1 \mathrm{~mol} / \mathrm{L}$ $\left.\left(\mathrm{NH}_{4}\right)_{2} \mathrm{TiF}_{6}\right)$ and proper calcinations temperature $\left(400^{\circ} \mathrm{C}\right)$ are favorable for the production of $\mathrm{TiO}_{2}$ nanotube films.
Doping of metal and nonmetal elements can improve the photocatalytic activity.

\section{Acknowledgments}

This work is financially supported by Beijing Municipal Commission of Education Key Foundation (KZ2010100050001); Beijing Innovation Talent Project (PHR201006101); Beijing New Century Hundred, Thousand and Ten Thousand Talent Project, State key Laboratory of Electronic Thin Films and Integrated Devices (UESTC: KFJJ201001) and Guangxi Natural Science Foundation (2010GXNSFB013009).

\section{References}

[1] N. M. Mahmoodi and M. Arami, "Degradation and toxicity reduction of textile wastewater using immobilized titania nanophotocatalysis," Journal of Photochemistry and Photobiology B, vol. 94, no. 1, pp. 20-24, 2009.

[2] F. Sayilkan, S. Erdemoǧlu, M. Asiltürk et al., "Photocatalytic performance of pure anatase nanocrystallite $\mathrm{TiO}_{2}$ synthesized under low temperature hydrothermal conditions," Materials Research Bulletin, vol. 41, no. 12, pp. 2276-2285, 2006.

[3] A. Fujishima and K. Honda, "Electrochemical photolysis of water at a semiconductor electrode," Nature, vol. 238, no. 5358, pp. 37-38, 1972.

[4] J. G. Yu, H. G. Yu, B. Cheng, and C. Trapalis, "Effects of calcination temperature on the microstructures and photocatalytic activity of titanate nanotubes," Journal of Molecular Catalysis A, vol. 249, no. 1-2, pp. 135-142, 2006.

[5] J. G. Yu, G. H. Wang, B. Cheng, and M. H. Zhou, "Effects of hydrothermal temperature and time on the photocatalytic activity and microstructures of bimodal mesoporous $\mathrm{TiO}_{2}$ 
powders," Applied Catalysis B, vol. 69, no. 3-4, pp. 171-180, 2007.

[6] J. A. Byrne, P. A. Fernandez-Ibanez, P. S. M. Dunlop, D. M. A. Alrousan, and J. W. J. Hamilton, "Photocatalytic enhancement for solar disinfection of water: a review," International Journal of Photoenergy, vol. 2011, Article ID 798051, 12 pages, 2011.

[7] C. C. Chang and W. C. Chen, "High-refractive-index thin films prepared from aminoalkoxysilane-capped pyromellitic dianhydride-titania hybrid materials," Journal of Polymer Science A, vol. 39, no. 19, pp. 3419-3427, 2001.

[8] S. K. Hazra and S. Basu, "High sensitivity and fast response hydrogen sensors based on electrochemically etched porous titania thin films," Sensors and Actuators B, vol. 115, no. 1, pp. 403-411, 2006.

[9] S. Q. Fan, C. J. Li, G. J. Yang, L. Z. Zhang, J. C. Gao, and Y. X. $\mathrm{Xi}$, "Fabrication of nano- $\mathrm{TiO}_{2}$ coating for dye-sensitized solar cell by vacuum cold spraying at room temperature," Journal of Thermal Spray Technology, vol. 16, no. 5-6, pp. 893-897, 2007.

[10] V. E. Nawin, S. Noriaki, C. Tawatchai, K. Takeyuki, and T. Wiwut, "A step towards length control of titanate nanotubes using hydrothermal reaction with sonication pretreatment," Nanotechnology, vol. 19, no. 3, pp. 1-6, 2008.

[11] R. R. Djenadic, L. M. Nikolic, K. P. Giannakopoulos, B. Stojanovic, and V. V. Srdic, "One-dimensional titanate nanostructures: synthesis and characterization," Journal of the European Ceramic Society, vol. 27, no. 13-15, pp. 4339-4343, 2007.

[12] C. K. Lee, C. C. Wang, M. D. Lyu, L. C. Juang, S. S. Liu, and S. H. Hung, "Effects of sodium content and calcination temperature on the morphology, structure and photocatalytic activity of nanotubular titanates," Journal of Colloid and Interface Science, vol. 316, no. 2, pp. 562-569, 2007.

[13] J. H. Zhang, X. Xiao, and J. M. Nan, "Hydrothermal-hydrolysis synthesis and photocatalytic properties of nano- $\mathrm{TiO}_{2}$ with an adjustable crystalline structure," Journal of Hazardous Materials, vol. 176, no. 1-3, pp. 617-622, 2010.

[14] M. C. Neves, J. M. F. Nogueira, T. Trindade, M. H. Mendonça, M. I. Pereira, and O. C. Monteiro, "Photosensitization of $\mathrm{TiO}_{2}$ by $\mathrm{Ag}_{2} \mathrm{~S}$ and its catalytic activity on phenol photodegradation," Journal of Photochemistry and Photobiology A, vol. 204, no. 2-3, pp. 168-173, 2009.

[15] Y. C. Yu, Y. X. Ding, S. L. Zuo, and J. J. Liu, "Photocatalytic activity of nanosized cadmium sulfides synthesized by complex compound thermolysis," International Journal of Photoenergy, vol. 2011, Article ID 762929, 5 pages, 2011.

[16] R. Azimirad, P. K. Hosravi, A. Z. Moshfegh et al., "Synthesis of $\mathrm{W}(17) \mathrm{O}(47)$ nanothick plates with preferred orientation and their photocatalytic activity," Surface and Interface Analysis, vol. 43, no. 11, pp. 1397-1402, 2011.

[17] J. S. Wang, S. Yin, and T. Sato, "Synthesis and characterization of fibrous $\mathrm{SrTiO}_{3}$ particles," Materials Science and Engineering $B$, vol. 131, no. 1-3, pp. 248-251, 2006.

[18] L. L. Costa and A. G. S. Prado, " $\mathrm{TiO}_{2}$ nanotubes as recyclable catalyst for efficient photocatalytic degradation of indigo carmine dye," Journal of Photochemistry and Photobiology A, vol. 201, no. 1, pp. 45-49, 2009.

[19] M. H. Seo, M. Yuasa, T. Kida, J. S. Huh, K. Shimanoe, and N. Yamazoe, "Gas sensing characteristics and porosity control of nanostructured films composed of $\mathrm{TiO}_{2}$ nanotubes," Sensors and Actuators B, vol. 137, no. 2, pp. 513-520, 2009.

[20] F. M. Wang, Z. S. Shi, F. Gong, J. T. Jiu, and M. Adachi, "Morphology control of anatase $\mathrm{TiO}_{2}$ by surfactant-assisted hydrothermal method $* *$ supported by the natural science foundation of tianjin (No.06YFJMJC05000)," Chinese Journal of Chemical Engineering, vol. 15, no. 5, pp. 754-759, 2007.

[21] C. Colmenares, R. Luque, J. M. Campelo, F. Colmenares, Z. Karpiński, and A. A. Romero, "Nanostructured photocatalysts and their applications in the photocatalytic transformation of lignocellulosic biomass: an overview," Materials, vol. 2, no. 4, pp. 2228-2258, 2009.

[22] Y. P. Guo, N. H. Lee, H. J. Oh et al., "Preparation of titanate nanotube thin film using hydrothermal method," Thin Solid Films, vol. 516, no. 23, pp. 8363-8371, 2008.

[23] D. L. Morgan, H. Y. Zhu, R. L. Forst, and E. R. Waclawik, "Determination of a morphological phase diagram of titania/titanate nanostructures from alkaline hydrothermal treatment of Degussa P25," Chemistry of Materials, vol. 20, no. 12, pp. 3800-3802, 2008.

[24] N. H. Lee, H. J. Oh, S. C. Jung, W. J. Lee, D. H. Kim, and S. J. Kim, "Photocatalytic properties of nanotubular-shaped $\mathrm{TiO}_{2}$ powders with anatase phase obtained from titanate nanotube powder through various thermal treatments," International Journal of Photoenergy, vol. 2011, Article ID 327821, 7 pages, 2011.

[25] G. Che, B. B. Lakshmi, E. R. Fisher, and C. R. Martin, "Carbon nanotubule membranes for electrochemical energy storage and production," Nature, vol. 393, no. 6683, pp. 346-349, 1998.

[26] H. Masuda, K. Nishio, and N. Baba, "Fabrication of porous $\mathrm{TiO}_{2}$ films using two-step replication of microstructure of anodic alumina," Japanese Journal of Applied Physics, vol. 31, no. 12, part 1, pp. L1775-L1777, 1992.

[27] B. B. Lakshmi, C. J. Patrissi, and C. R. Martin, "Sol-Gel Template Synthesis of Semiconductor Oxide Micro- and Nanostructures," Chemistry of Materials, vol. 9, no. 11, pp. 25442550, 1997.

[28] J. P. Tu, L. P. Zhu, K. Hou, and S. Y. Guo, "Synthesis and frictional properties of array film of amorphous carbon nanofibers on anodic aluminum oxide," Carbon, vol. 41, no. 6, pp. 1257-1263, 2003.

[29] Y. Yang, Z. Hu, Q. Wu, Y. N. Lü, X. Z. Wang, and Y. Chen, "Template-confined growth and structural characterization of amorphous carbon nanotubes," Chemical Physics Letters, vol. 373, no. 5-6, pp. 580-585, 2003.

[30] S. Z. Chu, K. Wada, S. Inoue, and S. Todoroki, "Fabrication of oxide nanostructures on glass by aluminum anodization and sol-gel process," Surface and Coatings Technology, vol. 169-170, no. 2, pp. 190-194, 2003.

[31] H. Imai, Y. Takei, K. Shimizu, M. Matsuda, and H. Hirashima, "Direct preparation of anatase $\mathrm{TiO} 2$ nanotubes in porous alumina membranes," Journal of Materials Chemistry, vol. 9, no. 12, pp. 2971-2972, 1999.

[32] H. Masuda and K. Fukuda, "Ordered metal nanohole arrays made by a two-step replication of honeycomb structures of anodic alumina," Science, vol. 268, no. 5216, pp. 1466-1468, 1995.

[33] H. Masuda and M. Satoh, "Fabrication of gold nanodot array using anodic porous alumina as an evaporation mask," Japanese Journal of Applied Physics, vol. 35, no. 1, pp. L126L129, 1996.

[34] A. P. Li, F. Muller, A. Birner, K. Nielsch, and U. Gösele, "Polycrystalline nanopore arrays with hexagonal ordering on aluminum," Journal of Vacuum Science and Technology A, vol. 17, no. 4, pp. 1428-1431, 1999.

[35] H. Asoh, K. Nishio, M. Nakao, A. Yokoo, T. Tamamura, and H. Masuda, "Fabrication of ideally ordered anodic porous 
alumina with $63 \mathrm{~nm}$ hole periodicity using sulfuric acid," Journal of Vacuum Science and Technology B, vol. 19, no. 2, pp. 569-572, 2001.

[36] P. P. Mardilovich, A. N. Govyadinov, N. I. Mukhurov, A. M. Rzhevskii, and R. Paterson, "New and modified anodic alumina membranes. Part I. Thermotreatment of anodic alumina membranes," Journal of Membrane Science, vol. 98, no. 1-2, pp. 131-142, 1995.

[37] T. Xu, G. Zangari, and R. M. Metzger, "Periodic holes with $10 \mathrm{~nm}$ diameter produced by grazing Ar+ milling of the barrier layer in hexagonally ordered nanoporous alumina," Nano Letters, vol. 2, no. 1, pp. 37-41, 2002.

[38] T. Kyotani, L. Tsai, A. Tomita et al., "Preparation of ultrafine carbon tubes in nanochannels of an anodic aluminum oxide film," Chemistry of Materials, vol. 8, no. 8, pp. 2109-2113, 1996.

[39] G. Che, B. B. Lakshmi, C. R. Martin, E. R. Fisher, and R. S. Ruoff, "Chemical vapor deposition based synthesis of carbon nanotubes and nanofibers using a template method," Chemistry of Materials, vol. 10, no. 1, pp. 260-267, 1998.

[40] J. Li, C. Papadopoulos, J. M. Xu, and M. Moskovits, "Highlyordered carbon nanotube arrays for electronics applications," Applied Physics Letters, vol. 75, no. 3, pp. 367-369, 1999.

[41] K. B. Shelimov and M. Moskovits, "Composite nanostructures based on template-grown boron nitride nanotubules," Chemistry of Materials, vol. 12, no. 1, pp. 250-254, 2000.

[42] G. Sauer, G. Brehm, S. Schneider et al., "Highly ordered monocrystalline silver nanowire arrays," Journal of Applied Physics, vol. 91, no. 5, pp. 3243-3247, 2002.

[43] Y. Kanamori, K. Hane, H. Sai, and H. Yugami, "100 nm period silicon antireflection structures fabricated using a porous alumina membrane mask," Applied Physics Letters, vol. 78, no. 2, pp. 142-143, 2001.

[44] S. Shingubara, O. Okino, Y. Murakami, H. Sakaue, and T. Takahagi, "Fabrication of nanohole array on Si using selforganized porous alumina mask," Journal of Vacuum Science and Technology B, vol. 19, no. 5, pp. 1901-1904, 2001.

[45] D. Crouse, Y. H. Lo, A. E. Miller, and M. Crouse, "Self-ordered pore structure of anodized aluminum on silicon and pattern transfer," Applied Physics Letters, vol. 76, no. 1, pp. 49-51, 2000.

[46] J. Y. Liang, H. Chik, A. J. Yin, and J. Xu, "Two-dimensional lateral superlattices of nanostructures: nonlithographic formation by anodic membrane template," Journal of Applied Physics, vol. 91, no. 4, p. 2544, 2002.

[47] M. K. Li, C. W. Wang, and H. L. Li, "Synthesis of ordered Si nanowire arrays in porous anodic aluminum oxide templates," Chinese Science Bulletin, vol. 46, no. 21, pp. 1793-1796, 2001.

[48] S. Yamanaka, T. Hamaguchi, H. Muta, K. Kurosaki, and M. Uno, "Fabrication of oxide nanohole arrays by a liquid phase deposition method," Journal of Alloys and Compounds, vol. 373, no. 1-2, pp. 312-315, 2004.

[49] W. F. Jiang, Y. H. Ling, X. D. Bai, H. Y. Li, and D. Q. Cang, "Insitu template synthesis of $\mathrm{TiO}_{2}$ array films on Al substrates," Rare Metal Materials and Engineering, vol. 36, no. 7, pp. 11781180, 2007.

[50] Y. C. Zhao, M. Chen, T. Xu, W. M. Liu, and X. Liu, "Preparation of porous anodic oxide film on aluminum and its aplication in synthesis of 1-dimensional nanomaterials," Chinese Journal of Chemical Physics, vol. 17, no. 4, pp. 369374, 2004.

[51] Z. Y. Liu, J. X. Chen, D. Z. Zhangm, and G. Q. Sun, "Investigation on nanostructural porous alumina with two dimension ordered arrangements," Journal of Sichuan University, vol. 38, no. 3, p. 374, 2001 .

[52] Y. T. Cui, J. S. Wang, H. Y. Li, and Z. Z. Wang, "Study on synthesis in situ and photocatalytic activity of $\mathrm{TiO}_{2}$ nanotubes array films," Journal of Inorganic Materials, vol. 23, no. 6, pp. 1259-1262, 2008.

[53] J. Zhang, J. E. Kielbasa, and D. L. Carroll, "Controllable fabrication of porous alumina templates for nanostructures synthesis," Materials Chemistry and Physics, vol. 122, no. 1, pp. 295-300, 2010.

[54] Y. T. Cui, J. S. Wang, H. Y. Li, and Z. Z. Wang, "Effects of AAO template on the surface microstructure of $\mathrm{TiO}_{2}$ nanoarray films fabricated by liquid phase deposition," Chinese Journal of Inorganic Chemistry, vol. 25, no. 7, pp. 1274-1278, 2009.

[55] J. G. Yu, G. P. Dai, and B. Cheng, "Effect of crystallization methods on morphology and photocatalytic activity of anodized $\mathrm{TiO}_{2}$ nanotube array films," Journal of Physical Chemistry C, vol. 114, no. 45, pp. 19378-19385, 2010.

[56] G. P. Dai, J. G. Yu, and G. Liu, "Synthesis and enhanced visiblelight photoelectrocatalytic activity of $\mathrm{p}-\mathrm{n}$ junction $\mathrm{BiOI} / \mathrm{TiO}_{2}$ nanotube arrays," The Journal of Physical Chemistry C, vol. 115, no. 15, pp. 7339-7346, 2011.

[57] L. Zhao, J. R. Ran, Z. Shu, G. T. Dai, P. C. Zhai, and S. M. Wang, "Effects of calcination temperatures on photocatalytic activity of ordered titanate nanoribbon $/ \mathrm{SnO}_{2}$ films fabricated during an EPD process," International Journal of Photoenergy, vol. 2012, Article ID 472958, 7 pages, 2012.

[58] W. F. Jiang, D. Q. Cang, S. J. Hao, Y. H. Ling, X. D. Bai, and Y. B. Zong, "Fabrication of $\mathrm{TiO}_{2}$ nanorod array film on $\mathrm{Al}$ plate by liquid phase deposition method," Materials Science and Engineering, vol. 24, no. 6, pp. 805-807, 2006.

[59] J. G. Yu, H. G. Yu, B. Cheng, X. J. Zhao, J. C. Yu, and W. K. Ho, "The effect of calcination temperature on the surface microstructure and photocatalytic activity of $\mathrm{TiO}_{2}$ thin films prepared by liquid phase deposition," Journal of Physical Chemistry B, vol. 107, no. 50, pp. 13871-13879, 2003.

[60] J. G. Yu and B. Wang, "Effect of calcination temperature on morphology and photoelectrochemical properties of anodized titanium dioxide nanotube arrays," Applied Catalysis B, vol. 94, no. 3-4, pp. 295-302, 2010.

[61] P. F. Xing, J. S. Wang, J. X. Jin, Z. Q. Zhang, and Z. H. Wang, "Preparation of S-N Co-doped $\mathrm{TiO}_{2}$ visible light photocatalysts by mechan-chemical method and its photocatalytic activity," Journal of Nanoscience and Nanotechnology, vol. 4, no. 2, pp. 29-33, 2007.

[62] L. Sun, J. Li, C. L. Wang et al., "Ultrasound aided photochemical synthesis of $\mathrm{Ag}$ loaded $\mathrm{TiO}_{2}$ nanotube arrays to enhance photocatalytic activity," Journal of Hazardous Materials, vol. 171, no. 1-3, pp. 1045-1050, 2009.

[63] Y. Okour, H. K. Shon, I. J. El Saliby, R. Naidu, J. B. Kim, and J. H. Kim, "Preparation and characterisation of titanium dioxide $\left(\mathrm{TiO}_{2}\right)$ and thiourea-doped titanate nanotubes prepared from wastewater flocculated sludge," Bioresource Technology, vol. 101, no. 5, pp. 1453-1458, 2009.

[64] J. J. Xu, Y. H. Ao, M. D. Chen, and D. G. Fu, "Low-temperature preparation of Boron-doped titania by hydrothermal method and its photocatalytic activity," Journal of Alloys and Compounds, vol. 484, no. 1-2, pp. 73-79, 2009.

[65] G. F. Shang, H. B. Fu, S. G. Yang, and T. G. Xu, "Mechanistic study of visible-light-induced photodegradation of 4chlorophenol by $\mathrm{TIO}_{2-x} \mathrm{~N}_{x}((0.021<x<0.049))$ with Low Nitrogen Concentration," International Journal of Photoenergy, vol. 2012, Article ID 759306, 9 pages, 2012. 
[66] R. Asahi, T. Morikawa, T. Ohwaki, K. Aoki, and Y. Taga, "Visible-light photocatalysis in nitrogen-doped titanium oxides," Science, vol. 293, no. 5528, pp. 269-271, 2001.

[67] A. Y. Bai, W. Liang, G. L. Zheng, and X. G. Zhao, "Photocatalytic properties under visible light of $\mathrm{S}$ and $\mathrm{N} \mathrm{Co-}$ doped titanium oxide films," Journal of Taiyuan University of Technology, vol. 42, no. 1, pp. 74-77, 2011.

[68] H. M. Zhao, Y. Chen, X. Quan, and X. L. Ruan, "Preparation of $\mathrm{Zn}$-doped $\mathrm{TiO}_{2}$ nanotubes electrode and its application in pentachlorophenol photoelectrocatalytic degradation," Chinese Science Bulletin, vol. 52, no. 11, pp. 1456-1461, 2007.

[69] J. Li, H. Yun, and C. J. Lin, “The Fe-doped $\mathrm{TiO}_{2}$ nanotube arrays as a photoanode for cathodic protection of stainless steel," Acta Physico, vol. 23, no. 12, pp. 1886-1892, 2007.

[70] Z. H. Xu and J. G. Yu, "Visible-light-induced photoelectrochemical behaviors of Fe-modified $\mathrm{TiO}_{2}$ nanotube arrays," Nanoscale, vol. 3, no. 8, pp. 3138-3144, 2011.

[71] T. H. Wang, Y. X. Li, S. Q. Peng, G. X. Lü, and S. B. Li, “Activity of rare earth doped $\mathrm{TiO}_{2}$ deposited with Pt for photocatalytic hydrogen generation," Acta Chimica Sinica, vol. 63, no. 9, pp. 797-801, 2005.

[72] J. Chen, M. Yao, and X. Wang, "Investigation of transition metal ion doping behaviors on $\mathrm{TiO}_{2}$ nanoparticles," Journal of Nanoparticle Research, vol. 10, no. 1, pp. 163-171, 2008.

[73] J. G. Yu, G. P. Dai, and B. B. Huang, "Fabrication and characterization of visible-light-driven plasmonic photocatalyst $\mathrm{Ag} / \mathrm{AgCl} / \mathrm{TiO}_{2}$ nanotube arrays," Journal of Physical Chemistry C, vol. 113, no. 37, pp. 16394-16401, 2009.

[74] L. Wu, J. C. Yu, and X. Z. Fu, "Characterization and photocatalytic mechanism of nanosized CdS coupled $\mathrm{TiO}_{2}$ nanocrystals under visible light irradiation," Journal of Molecular Catalysis A, vol. 244, no. 1-2, pp. 25-32, 2006.

[75] D. R. Catal, "Photosensitization of $\mathrm{TiO}_{2}$ by $\mathrm{MxOy}$ and MxSy nanoparticles for heterogeneous photocatalysis applications," Catalysis Today, vol. 122, no. 1-2, pp. 20-26, 2007.

[76] K. K. Akurati, A. Vital, J. P. Dellemann et al., "Flame-made $\mathrm{WO}_{3} / \mathrm{TiO}_{2}$ nanoparticles: relation between surface acidity, structure and photocatalytic activity," Applied Catalysis B, vol. 79, no. 1-2, pp. 53-62, 2008.

[77] J. He, Q. Luo, Q. Z. Cai, X. W. Li, and D. Q. Zhang, "Microstructure and photocatalytic properties of $\mathrm{WO}_{3} / \mathrm{TiO}_{2}$ composite films by plasma electrolytic oxidation," Materials Chemistry and Physics, vol. 129, no. 1-2, pp. 242-248, 2011.

[78] Z. Z. Wang, J. S. Wang, H. Y. Li, G. S. Sun, and K. L. Huang, "Fabrication and photocatalytic activity of $\mathrm{TiO}_{2} / \mathrm{SiO}_{2}$ composite nanotubes," Chemical Intermediate, vol. 37, no. 2, pp. 541-549, 2011. 


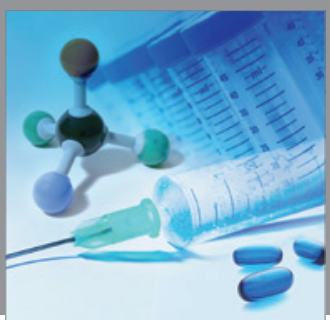

International Journal of

Medicinal Chemistry

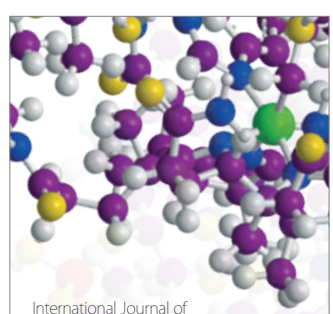

Carbohydrate Chemistry

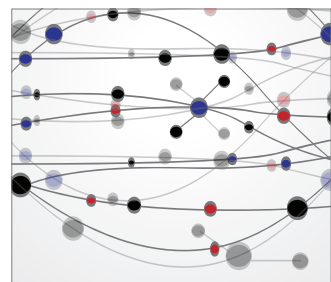

The Scientific World Journal
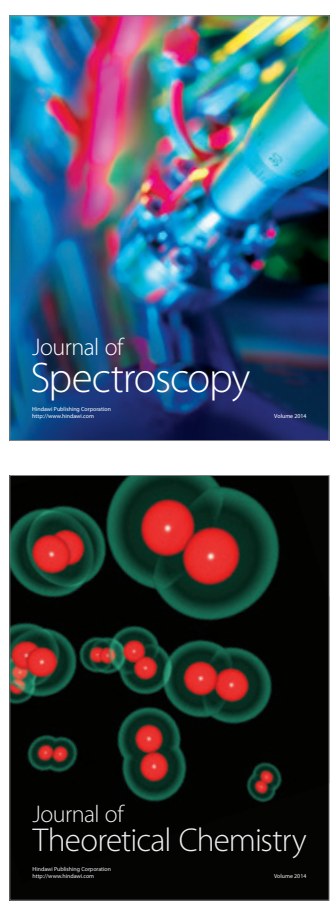
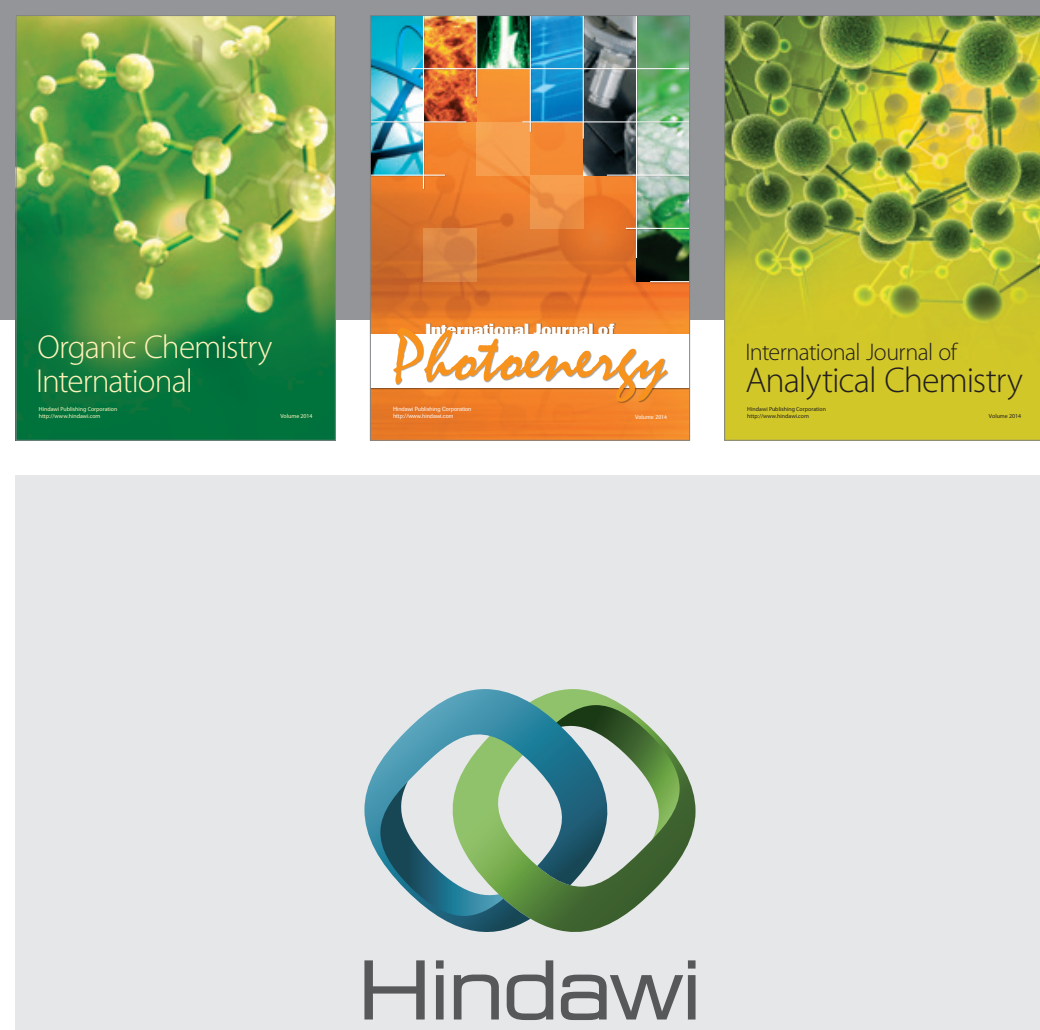

Submit your manuscripts at

http://www.hindawi.com
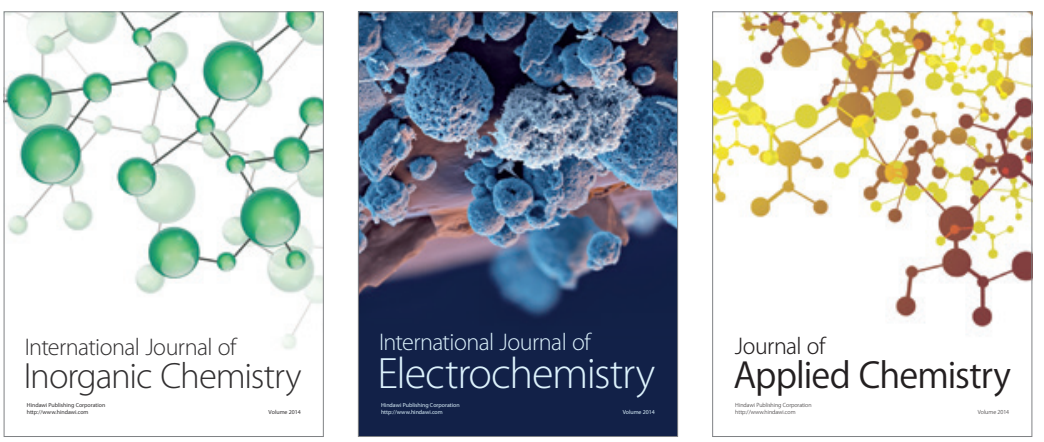

Journal of

Applied Chemistry
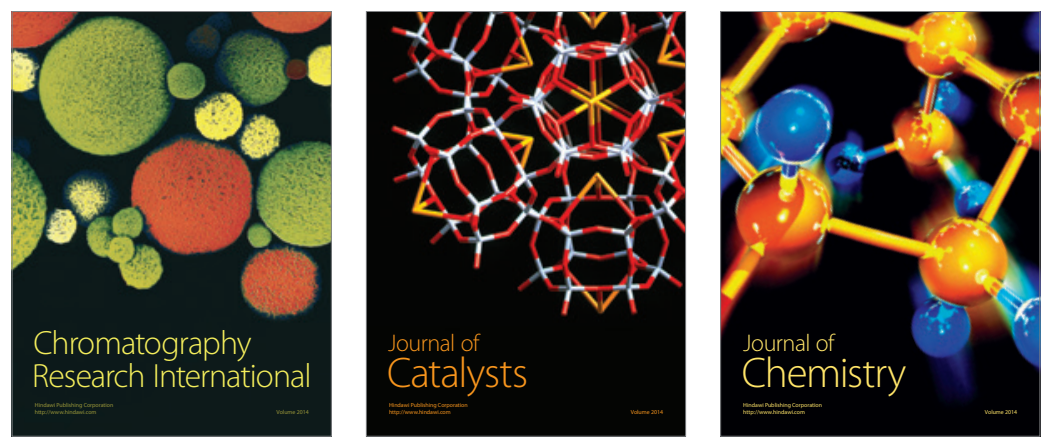
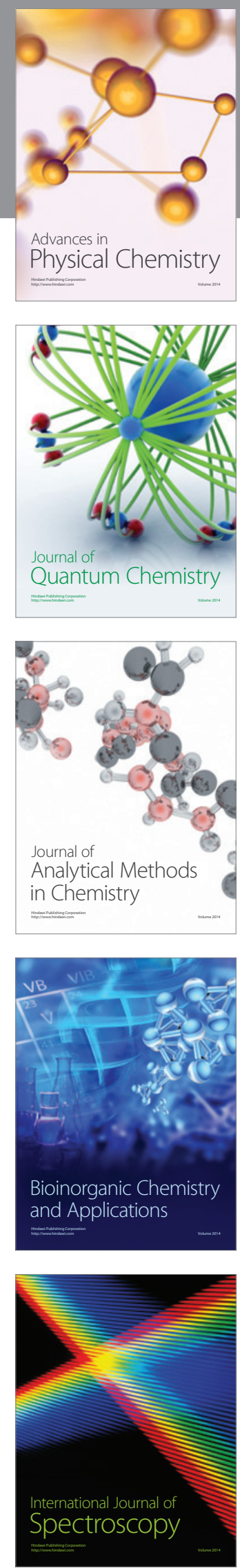